\title{
Effect of green tea consumption on level of glucose, lipid profile and kidney functions in alloxan induced-diabetic rats
}

\author{
Abd-Elraheim A. Elshater ; Muhammad M. A. Salman; Mahrous M. A. Moussa \\ South Valley University, Faculty of Science, Zoology Department, Qena
}

\section{ABSTRACT}

In recent years, green tea has become a subject of interest because of its beneficial effects on human health. The purpose of the present study was to investigate the effects of daily oral administration of green tea extract for 6 weeks on plasma glucose, lipid profile and kidney functions in alloxan-induced diabetic rats to show the preventive and curative effects of green tea.

Rats (130-150 g) were divided into 4 groups, normal control rats, diabetic rats, diabetic rats post-treated with green tea and diabetic rats pretreated with green tea. Green tea extract was administered orally for 6 weeks to the third and forth groups (300 mg/kg b.w,). Plasma glucose, triglycerides, HDL and LDL-cholesterol were significantly reduced in post-treated and pre-treated groups while plasma cholesterol was significantly reduced only in post-treated group while plasma creatinine, urea and uric acid levels were significantly reduced in post-treated diabetic group, but in the pre-treated group creatinine and uric acid levels were reduced, but urea level did not change. It is concluded that the consumption of green tea produced a significant reduction in glucose level in diabetic rats. In addition green tea is capable of improving hyperlipidaemia and the impaired kidney functions in addition to its hyperglycemic control.

Key words: green tea, plasma, diabetic rats, lipids, glucose, urea, creatinine, uric acid

\section{INTRODUCTION}

Diabetes mellitus is a common disorder associated with markedly increased morbidity and mortality rate. Diabetes mellitus can be defined as a group of metabolic disease characterized by chronic hyperglycemia resulting from defects in insulin secretion, insulin action or both resulting in impaired function in carbohydrate, lipid and protein metabolism (Zhang et al. 2006).

Green tea (Camellia sinensis) has a long history as a folk remedy, and it is the most widely consumed beverage in the world but the beneficial medicinal properties have only been elucidated in the past 20 years (Vinson and Zhang, 2005). Recently green tea is being widely studied for its beneficial effects in the treatment and prevention of human diseases Green tea extracts contain a number of components including catechins, saponins and flavonoids, and it has been demonstrated that catechins can reduce cellular oxidation (Hara, 2001), blood glucose level (Matsumoto et al., 1993) and cholesterol absorption (Ikeda et al., 1992). Therefore, it has been expected that an intake of green tea extract will prevent or delay the onset of diseases such as cardiovascular diseases diabetes and cancer (Imai et al., 1997). Flavonoids are known to be effective in removing individual oxygen and free radicals from the lipids peroxidation step (Blasig et al., 1987). Polysaccharides of green tea have also been reported to have hypoglycemic activities (Wang et al., 2000). Great advanced studies have been made to reveal the hypoglycemic effect of tea polysaccharides (Wang et al., 
2001). An epidemiological study made by Mennen et al. (2003) with 3000 subjects showed that increased tea drinking is significantly associated with lower levels of serum glucose and triglycerides. Green tea has been reported to reduce body weight, body mass index and body fat (Tsuchida et al., 2002) and serum cholesterol level (Imai and Nakachi, 1995), In addition, Babu et al. (2007) showed that green tea consumption reduce the blood glucose as well as total cholesterol level and body fat, also he suggested that green tea may be effective in preventing the development of not only diabetes but also cardiovascular diseases. Green tea given to normal rats at a high dose decreased plasma glucose, and triglycerides (Wu et al., 2004).

Tokunagag et al. (2002) showed that green tea consumption has a lowering effect on plasma cholesterol and triglycerides levels. Erba et al. (2005) studied the effect of moderate intake of green tea on human health and they found a significant decrease in LDL-cholesterol. Catechins extracted from green tea have been shown to normalize plasma cholesterol concentration without affecting HDL-cholesterol concentration, growth rate and food efficiency in rats (Muramatso et al., 1986). It has been also reported that ingestion of tea catechins inhibits absorption of lipids/glucose (Matsumoto et al. (1993). Raederstorff et al. (2003) reported that green tea exerts hypolipidaemic actions. Tas et al. (2005) reported that green tea inhibited copperinduced oxidation of low-density lipoprotein (LDL). Furthermore, the polyphenols in green tea have an antioxidant activity towards low-density lipoprotein (LDL) (Miura et al., 2000). Yokozawa et al. (2002) found that administration of green tea polyphenol markedly reduced the susceptibility of LDL to oxidation. Extract of catechin from green tea was found to decrease the total cholesterol and LDL-fraction (Zdunczyk et al., 2002).

Plasma Creatinine and blood urea nitrogen levels were found to be reduced by the administration of green tea polyphenols in alloxan-induced diabetic rats (Sabu et al., 2002). Clark et al. (2004) reported that diabetic rats treated with green tea showed a significant reduction in creatinine level, but blood urea statistically did not change. The anti-platelet cohesion action of catechin enables the kidney malfunctions resulting from diabetes to return to a normal state (Kwag et al., 2001).

The aim of the present study was to investigate the effects of daily oral consumption of green tea extract for 6 weeks on plasma glucose, lipid profile and kidney functions in alloxan-induced diabetic rats to show the curative and preventive effects of green tea.

\section{MATERIAL AND METHODS}

\section{Green tea extract:}

Green tea was purchased from a local market and stored in dry atmosphere and identified by the herbarium staff of Botany department, University of Assuit, Egypt. Green tea extract was prepared by the modified method of Yang et al. (2001). Green tea leaves were ground in a miller, at temperature less than $50 \mathrm{C}^{\circ}$ Tea powder was extracted with $95 \%$ ethanol $(1: 10 \mathrm{w} / \mathrm{v})$ for two days with constant stir. Suspensions were filtered through Whatman filter paper NO.1 to retain the clear solution, the residue was extracted again, and the pooled tea extract evaporated under vacuum below $5^{\circ} \mathrm{C}$. The extract was stored at $4{ }^{\circ} \mathrm{C}$.

\section{Induction of diabetes:}

Male Wistar rats weighting from $(130-150 \mathrm{~g})$ were housed in standard conditions and fed with normal diet and water ad libitum .Diabetes was induced in fasting rats $12 \mathrm{~h}$ by a single intraperitoneal dose of $150 \mathrm{mg} / \mathrm{kg}$ b.w. of alloxan. After 
the injection, they had free access of food and water; the rats were given $5 \%$ glucose solution after $6 \mathrm{~h}$. from alloxan injection to drink overnight to counter any hypoglycemic shock. The diabetic state was assessed by measuring the fasting plasma glucose concentration $72 \mathrm{~h}$. after alloxan treatment in fasting rats. The rats with a plasma glucose level above $250 \mathrm{mg} / \mathrm{dl}$ were selected for the experiment and considered as diabetic (Zhang et al., 2004).

\section{Experimental protocol:}

The experimental animals were divided into 4 groups; each group contained 10 animals: Control group (normal without treatment), diabetic group (injected with $150 \mathrm{mg} / \mathrm{kg}$ b.w of alloxan), post-treated group (the rats first were injected with alloxan then given green tea) for 6 weeks, pretreated group (first, the rats were given green tea for 6 weeks then injected with alloxan). Green tea extract was given orally to the rats through a gastric tube daily for 6 weeks at a dose of $300 \mathrm{mg} / \mathrm{kg} \mathrm{b}$. w

\section{Collection of blood samples:}

At the end of the 6 weeks post-treatment, blood samples were collected by sacrificing the animals by decapitation and blood was collected in clean EDTA tubes, then plasma was separated by centrifugation and stored at $-20^{\circ} \mathrm{C}$.for biochemical analysis. The pretreated rats with green tea were decapitated after 3 days from the injection of alloxan and blood samples were collected as mentioned above. Chemicals:

Alloxan monohydrate was obtained from Sigma Chemicals Company, Egypt. Kits of glucose, cholesterol, triglycerides, HDL, creatinine, urea and uric acid were purchased from Spinreact, S.A. Ctra. Santa Coloma, Spain. All other chemicals used were of analytical reagent grade.

\section{Biochemical analysis:} (1969).

Glucose determination was carried out according to the method of Trinder,

Cholesterol was determined by the enzymatic method as described by Richmond, (1973), while Triglycerides were determined by the enzymatic colorimetric method as described by Young, (2001).

Low density lipoproteins (LDL) and very low density lipoproteins (VLDL) was determined as described by Lopes-Virella, (1977) Creatinine was determined by kinetic method described by Hare, (1950), while determination of urea was according to the enzymatic method of Patton, and crouch (1977).Plasma uric acid was determined by the quantitative determination method of Young, (2001).

\section{Statistical analysis:}

Data were statistically analyzed by one-way analysis of variance followed by Duncant's test (PC-stat computer program). Significant difference (L.S.D) was used to test the differences among treatments. Results were considered statistically significant when $(\mathrm{P}<0.05)$.

\section{RESULTS}

\section{Effect of green tea extract on diabetic rats: Glucose:}

Administration of green tea extract to the alloxan-induced diabetic rats significantly decreased the elevation of blood glucose levels in post-treated and pretreated rats with green tea, when compared with the diabetic rats. Treatment with green tea did not decrease blood glucose levels to be like normal, but it is still 
significantly higher than normal Table 1, (i.e) the inhibitory effect of green tea extract on hyperglycemia, induced by alloxan, was statistically significant.

\section{Lipid profile:}

From Table 1 it is shown that, injection of alloxan in normal rats produced significant increase in plasma cholesterol, triglycerides and LDL-cholesterol levels compared with normal rats, but plasma HDL-cholesterol level slightly decreased when compared with normal rats. While post-treatment of diabetic rats with green tea extract significantly reduced plasma cholesterol and LDL-cholesterol levels when compared to both diabetic and normal rats, but triglyceride and HDL-cholesterol levels were significantly reduced compared with diabetic rats only and they were near to normal levels, as shown in Table 1 . Pre-treatment with green tea did not prevent the elevation of plasma cholesterol level, and statistically it was not changed when compared with diabetic rats, and still significantly higher than normal, while plasma triglycerides and LDL-cholesterol levels were significantly decreased when compared with diabetic rats, but triglycerids is still significantly higher than normal, and LDL decreased than normal rats. In contrast, HDL-cholesterol level was significantly increased when compared with normal and diabetic rats. This means that, pretreatment with green tea decreases LDL-cholesterol only.

\section{Creatinine, urea and uric acid:}

Post-administration of green tea extract to diabetic rats recorded a significant reduction in the levels of plasma creatinine, urea and uric acid when compared with diabetic rats, but plasma urea is still significantly higher than the normal rats, while, administration of green tea extract normalized the levels of plasma creatinine and uric acid, as shown in Table 1.

It is also observed that, pre-administration of green tea extract to diabetic rats recorded a significant reduction in the levels of plasma creatinine and uric acid when compared with diabetic rats, but they are still significantly higher than normal rats, while plasma urea level did not change when compared with diabetic rats, and it is still significantly higher than normal.

Table I: Effect of post-treatment and pre-treatment with green tea extract $300 \mathrm{mg} / \mathrm{kg}$ b.w. on the levels of plasma glucose, lipids profile, Creatinine, urea and uric acid in alloxan -induced diabetic rats.

\begin{tabular}{|c|c|c|c|c|}
\hline $\begin{array}{c}\text { parameters } \\
\mathbf{m g} / \mathbf{d l}\end{array}$ & $\begin{array}{c}\text { normal group } \\
\mathbf{M} \pm \mathbf{S . E}\end{array}$ & $\begin{array}{c}\text { Diabetic control } \\
\text { gr oup } \mathbf{M} \pm \mathbf{S . E}\end{array}$ & $\begin{array}{c}\text { Post-treated group } \\
\text { (alloxan pre green tea } \\
\text { treatment) } \mathbf{M} \pm \mathbf{S . E}\end{array}$ & $\begin{array}{c}\text { re-treated group } \\
\text { (Green tea pre alloxan } \\
\text { treatment) } \mathbf{M} \pm \mathbf{S . E}\end{array}$ \\
\hline Glucose & $105.8 \pm 6.0$ & $353.8 \pm 6.1^{*}$ & $196.7 \pm 2.7^{* \#}$ & $217.8 \pm 4.7^{* \#}$ \\
\hline Cholesterol & $104.8 \pm 1.7$ & $126.2 \pm 4.0^{*}$ & $77.9 \pm 2.0^{* \#}$ & $124.5 \pm 1.5^{*}$ \\
\hline Triglycerides & $63.6 \pm 4.4$ & $137.9 \pm 4.7^{*}$ & $65.2 \pm 1.3^{\#}$ & $123.2 \pm 3.0^{* \#}$ \\
\hline HDL.Ch. & $56.5 \pm 3.6$ & $49.6 \pm 2.0$ & $60.2 \pm 1.4^{\#}$ & $78.8 \pm 1.1^{* \#}$ \\
\hline LDL.Ch. & $35.6 \pm 3.3$ & $49.1 \pm 3.2^{*}$ & $26.7 \pm 0.6^{* \#}$ & $25.0 \pm 0.2^{* \#}$ \\
\hline Creatinine & $0.47 \pm 0.04$ & $8.8 \pm 0.4^{*}$ & $0.7 \pm 0.03^{\#}$ & $2.5 \pm 0.1^{* \#}$ \\
\hline Urea & $29.8 \pm 1.7$ & $76.5 \pm 3.2^{*}$ & $60.2 \pm 3.9^{* \#}$ & $77.6 \pm 2.4^{*}$ \\
\hline Uric acid & $1.6 \pm 0.1$ & $4.8 \pm 0.3^{*}$ & $1.7 \pm 0.1^{\#}$ & $2.8 \pm 0.1^{* \#}$ \\
\hline
\end{tabular}

Values are expressed as mean \pm S.E of 10 animals.

Diabetic control is compared with normal.

Treated groups are compared with diabetic control

* Values are statistically significant $\mathrm{P}^{*}<0.05$ when compared with normal.

\# Values are statistically significant $\mathrm{P}^{\#}<0.05$ when compared with diabetic control. 


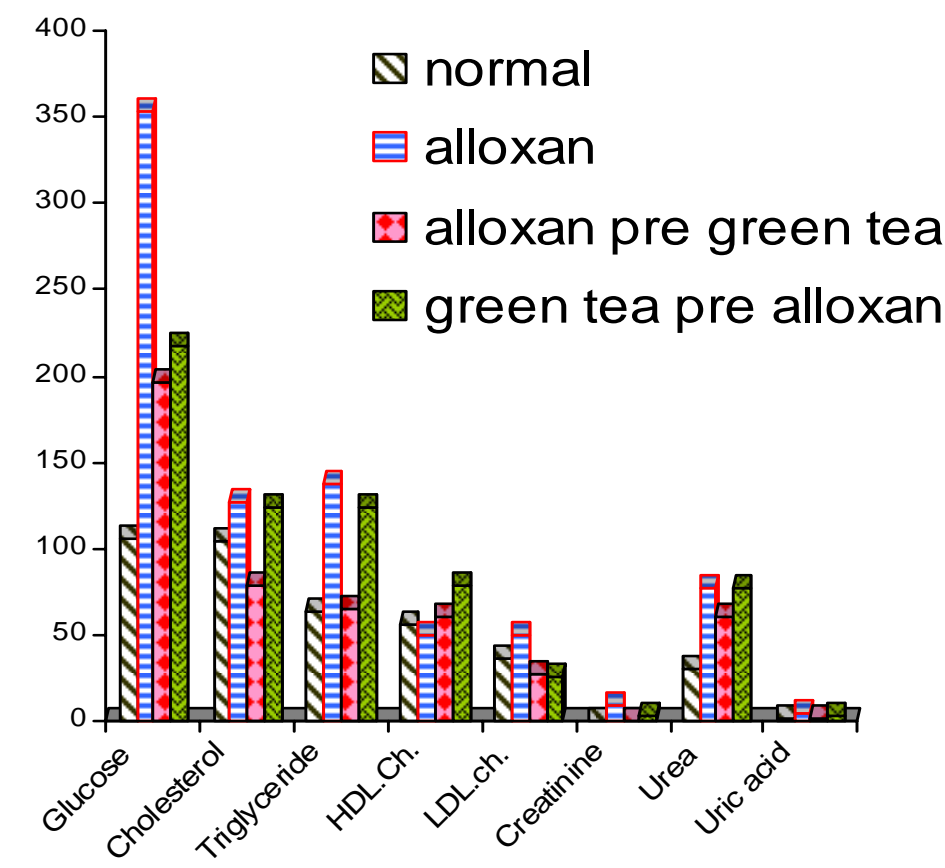

Fig. 1: Effect of post-treatment and pre-treatment with green tea extract $300 \mathrm{mg} / \mathrm{kg} \mathrm{b.w.} \mathrm{on} \mathrm{the} \mathrm{levels}$ of plasma glucose, lipid profile, Creatinine, urea and uric acid in alloxan -induced diabetic rats.

\section{DISCUSSION}

The present study revealed that green tea extract possesses both preventive and curative effects on diabetic rats. These findings are in agreement with other investigators. Gomes et al. (1995) and Wu et al. (2004) found that rats receiving green tea extract showed rapid normalization of blood glucose level in comparison to diabetic rats, and they suggested that tea extracts possibly protect the $\beta$-cells from the toxic effect of streptozotocin and also help regeneration of the damaged cells. It is also documented that the water soluble polysaccharides fraction of green tea is responsible for its anitdiabetic effect (Isigaki et al., 1991). It has been reported that green tea polyphenols increase insulin activity in diabetic rats (Anderson and Polansky, (2002).

Intestinal glucose uptake is mainly accomplished by the sodium-dependent glucose transporter, which was markedly inhibited by green tea polyphenols, thus decreasing the intestinal absorption of glucose which leads to hyperglycemia (Shimizu et al., 2000). In the present study, diabetic rats showed constant fasting hyperglycemia throughout the study and the administration of green tea extract to diabetic rats reduced the elevation of blood glucose, these are in agreement with the study of Tsuneki et al. (2004).and Babu et al. (2006) who found that the green tea reduced blood glucose level in both type 1 and type 2 of diabetic rats models. The antihyperglycemic effect of green tea constituents was ascribed to the activities of basal insulin (Wu et al., 2004), inhibition of intestinal glucose transporter (Kobayashi et al., 2000) and decrease the expression of genes that control gluconeogenesis (Waltner-Law et al., 2002).

Some studies have shown that catechins can inhibit digestive enzymes such as salivary amylase, intestinal sucrase and $\alpha$-glucosidase, suggesting that the reduced digestibility action of catechins may be responsible for lowering blood glucose levels 
in diabetic rats, and these mechanisms may be responsible for the anti-hyperglycemic effect of green tea (Liao et al., 2001). It has been reported that the insulin-like action of polyphenols is involved in the mechanism by which green tea decreases the blood glucose level (Hosoda et al., 2003). Alloxan produces oxygen radicals in the body, which cause pancreatic injury which is responsible for increased blood glucose seen in the diabetic rats (Halliwell and Gutteridge, 1985). Sabu et al. (2002) indicated that diabetes induced by alloxan was reversed by simultaneous administration of green tea polyphenol.

The present study revealed that green tea extract normalized cholesterol, triglycerides and LDL-cholesterol below the levels obtained in the diabetic rats after 6 weeks of treatment, but the extract did not prevent the elevation of HDL-cholesterol when compared with diabetic rats. Previous studies showed that catechin extracted from green tea normalized plasma cholesterol concentration without affecting HDLcholesterol concentration in rats (Cao and Cao, 1999) and also decreases the total cholesterol and LDL fraction (Zdunczyk et al., 2002).It was reported that green tea exerts hypolipidaemic action and its extract normalized plasma triglycerides and cholesterol concentration (Raederstorff et al., 2003). Aviram et al. (1998) reported that paraoxonase (PON1) is an antioxidant enzyme that protects lipoproteins against oxidative modification. Green tea might directly increase serum paraoxonase activity because antioxidant molecules such as flavonoids were shown to preserve paraoxonase activity (Aviram et al. 2004). Tas et al. (2005) suggested that green tea might also exert its beneficial effects on serum paraoxonase activity by its antihyperglycemic, antihyperlipidaemic and, thus, antioxidative action. Furthermore, Raederstorff et al. (2003) suggested that green tea might decrease intestinal absorption of lipids. Also it was reported that diabetes is seriously related to oxidative stress and diabetic patients are more sensitive to oxidative stress than healthy individuals (Baynes, 1991). Furthermore, oxidative imbalance, in which free radical removers are weakened and free radical generators are activated, promotes the generation of oxidized low-density lipoprotein (oxi-LDL) (Steinberg et al., 1989).

Stanely Mainzen Prince et al. (2004) had noticed the elevation of serum lipids in alloxan-induced diabetic rats, and reported that lipids play an important role in the pathogenesis of diabetes mellitus. The abnormal high concentration of serum lipids in diabetes is mainly due to the increase in the mobilization of free fatty acids from the peripheral depots due to insulin absence, since insulin inhibits the hormone sensitive lipase and catecholamine. The marked hyperlipedaemia that characterizes the diabetic state may therefore be regarded as a consequence of the uninhibited actions of lipolytic hormones on the fat depots (Al-Shamaony et al., 1994). Rupasinghe et al. (2003) reported that saponins, flavonoids, phenolic compounds and glycosides have hypolipidaemic and hypocholesterolaemic effects (Rupasinghe et al., 2003). Hence, it may be concluded that the hypolipidaemic effect produced by the green tea extract may be due to the presence of flavonoids, saponins and glycosides.

Plasma uric acid and creatinine can be used as a rough index of the glomerular filtration rate (Hernandz and Coulson, 1967). High levels of uric acid and creatinine indicates several disturbances in kidney (Maxine and Benjamin, 1985). In the present study alloxan-induced diabetes caused increasing plasma levels of creatinine, urea and uric acid, and also alloxan produces oxygen radicals and oxidative stress in the body, (Halliwell and Gutteridge, 1985). Choi et al. (2004) reported that the catechin in green tea is clearly effective in reducing oxidative stress and inflammatory reactions in kidney tissue. Another interpretation made by Kwag et al. (2001) was reported that green tea catechin has been found to improve the ratio of prostaglandin 
$\mathrm{I}_{2} /$ thromboxane $\mathrm{A}_{2}$ by controlling the cyclooxygenase way of the arachidonic acid in the microsomes and glomeruli of diabetic rat kidney. Therefore the catechin enables the kidney malfunctions resulting from diabetes to return to normal state.

It is concluded that the consumption of green tea produced a significant reduction in glucose level of diabetic rats. Also green tea is capable of improving hyperlipidaemia and the impaired kidney functions. In addition, the pretreatment of rats with green tea for 6 weeks before induced diabetes is effective in controlling the hyperglycemia and hyperlipidaemia.

\section{REFERENCES}

Al-Shamaony, L., Al-khazrajoi, S.M., \& Twaij, H.A.A., (1994). Hypoglycemic effect of Artemisia herba alba. II. Effect of a valuable extract on some blood parameters in diabetic animals. J. Ethnopharmacol., 43: 167-171.

Anderson, R.A., \& Polansky, N.M., (2002). Tea enhances insulin activity. J. Agric. Food Chem. 50: 7182-7186.

Aviram, M., Rosenblat, M., Bisgaier, C.L., Newton, R.S., Primo-Parmo, S.L., \& La Du, B.N., (1998). Paraoxonase inhibits high-density lipoprotein oxidation and preserves its function: a possible peroxidative role for paraoxonase. J. Clin. Invest. 101: 1581-1590.

Aviram, M., Rosenblat, M., Gaitini, D., Nitecki, s., Hoffman, A., Dornfeld, L., et al., (2004). Pomegranate juice consumption for 3 years by patients with carotid artery stenosis reduces common carotid intima-media thickness, blood pressure and LDL oxidation. Clin. Nutr. 23:423-433.

Babu, P.V.A., Sabitha, K.E., \& Shyamaladevi, C.S., (2006). Therapeutic effect of green tea extract on advanced glycation and cross-linking of collagen in the aorta of streptozotocin diabetic rats. Clin. Exp. Pharmacol. Physiol. 33: 351357.

Babu, P.V.A., Sabitha, K.E., Srinivasan, P., \& Shyamaladevi, C.S., (2007). Green tea attenuates diabetes induced Maillard-type fluorescence and collagen crosslinking in the heart of streptozotocin diabetic rats. Pharmacological Research 55:433-440.

Baynes, J.W., (1991). Role of oxidative stress in the development of complication in diabetes. Diabetes 40: 405-421.

Blasig, I.E., Lowe, H., \& Ebert, B., (1987). Radical trapping and lipid peroxidation during myocardial reperfusion injury-Radical scavenging by troxerutin in comparison to mannitol. Biomed. Biochem. Acta. 46: S539-S544.

Choi, J.H., Chai, Y.M., joo, G.J., Rhee, I.K., Lee, I.S., Kim, K.R., Choi, M.S., \& Rhee, S.J., (2004). Effects of Green Tea Catechin on Polymorphonuclear Leukocyte 5'-Lipoxygenase Activity, Leukotriene B4 Synthesis and Renal Damage in Diabetic Rats. Ann. Nutr. Meat. 48:151-155.

Clark, T.A., Heyliger, C.E., Edel, A.L., Goel, D.P., \& Pierce, G.N., (2004). Codelivery of a Tea Extract Prevents Morbidity and Mortality Associated With Oral Vanadate Therapy in Streptozotocin-Induced Diabetic Rats. Metabolism, 1 53: (9) 1145-1151.

Erba, D., Riso, Patrizia, Bordoni, A., Foti, P., Biagi, P.L., \& Testolin, G., (2005). Effectiveness of moderate green tea consumption on antioxidative status and plasma lipid profile in humans. J. Nutr. Biochem 16: 144-149. 
Gomes, A., Vedasiromoni, J.R., Das, M., Sharma, R.M., \& Ganguly, D.K., (1995). Anti-hyperglycemic effect of black tea (Camellia sinensis) in rats. J. Ethnopharmacol. 45: 223-226.

Halliwell, B., \& Gutteridge, J.M.C., (1985). Free Radicals in Biology and Medicine. Clarendon press, Oxford, London, pp. 22-35.

Hara, Y., (2001). Antioxidative Action of tea Polyphenols: Green tea. In Hara Y. (ed.): New York, Dekker, pp 26-40.

Hare, R.S., (1950). Endogenous creatinine in serum and urine. Pro. Soc. Exp. Biol. Med., 147-148.

Hernandz, T., \& Coulson, R.A., (1967). Amino acid excretion in the alligator. Comp. Biochem. Physiol. 23:775-784.

Hosoda, K., Iha, M., Wang, M.-F., Clevidence, B., Liao, M.-L., Yamamoto, S., \& Chuang, C.-K., (2003). Antihyperglycemic of oolong tea in type 2 diabetes. Diabetes Care 26 : 1714-1718.

Ikeda, I., Imasato, Y., Sasaki, E., Nakayama, M., Nagao, H., Takeo, T., Yayabe, F., \& Suugano, M., (1992). Tea catechins decrease micellar solubility and intestinal absorption of cholesterol in rats. Biochem. Biophys. Acta. 1127:141-146.

Imai, K., \& Nakachi, K., (1995). Cross sectional study of effects of drinking green tea on cardiovascular and liver diseases. BMJ 310 (6981) 693-696.

Imai, K., Suga, K., \& Nakachi, K., (1997). Cancer-preventive effects of drinking green tea among a Japanese population. Prev. Med. 26: 769-775.

Isigaki, K., Takakuwa, T., \& Takeo, T. (1991). Anti-diabetes mellitus effect of watersoluble tea polysaccharide. In Proceedings of international symposium on tea science (1991), Shizuka, Japan: The Organizing Committee of ISTS. pp. 240241.

Kobayashi, Y., Suzuki, M., Satsu, H., (2000). Green tea polyphenols inhibit the sodium dependent glucose transporter of intestinal epithelial cells by a competitive mechanism. J agric Food Chem 48: 618-623.

Kwag, O.G., Kim, S.O., Choi, J.H., Rhee, I.K., Choi, M.S., \& Rhee, S.J., (2001). Vitamin E improves microsomal Phospholipase A2 activity and the arachidonic acid cascade in kidney of diabetic rats. J. Nutr. 131: 1297-1301.

Liao, S., Kao, Y.H., \& Hiipakka, R.A., (2001). Green tea: biochemical and biological basis for health benefits. Vitam. Horm. 62:1-94.

Lopes-Virella, M.F, (1977). Clin. Chem. 23:882.

Matsumoto, N., Ishigaki, F., Ishigaki, A., Iwashina, H., \& Hard, Y., (1993). Reduction of blood glucose levels by tea catechin. Biosci. Biotech. Biochem. 57: 525527.

Maxine, M., \& Benjamin, B S., (1985). Outline of veterinary clinical pathology. 3rd edition, Colorado state university, printed in India at Rakha printers PVT. LTD., New Delhi.

Mennen, L.I.; Malvy, D.; Galan, P.; Preziosi, P.; Bertrais, S.; Bruckert, E.; Maurel, M.; Franchisseur, C., \& Hercberg, S., (2003). Tea consumption and cardiovascular risk in the SU.VI.MAX study: Are life-style factors important? Nutr. Res. 23: 879-890.

Miura, Y., Chiba, T., Miura, S., Tomita, I., Umegaki, K., Ikeda, M., \& Tomita, T., (2000). Green tea polyphenols (flavan 3-ols) prevent oxidative modification of low density lipoproteins: An ex vivo study in humans. J. Nutr. Biochem. 11: 216-222. 
Muramatso, K.; Fukuyo, M., \& Hara, Y., (1986). Effect of green tea catechins on plasma cholesterol level in cholesterol-fed rats. J. Nutr. Sci. Vitaminol. 32:613-622. Patton, C.J.and Crouch, S.R., (1977). Anal. Chem. 49: 464-469.

Raederstorff, D.G., Schlachter, M.F., Elste, V., \& Weber, P., (2003). Effect of EGCG on lipid absorption and plasma lipid levels in rats. J. Nutr. Biochem. 14: 326332.

Richmond, W., (1973). Preparation of properties of the cholesterol oxidase from nacordia sp. And its application to the enzymatic assay of total cholesterol in serum. Clin. Chem. 19: 1350-1356.

Rupasinghe, H.P., Jackson, C.J., Poysa, V., DiBerado, C., Bewely, J.D., \& Jenkinson, J., (2003). Soasapogenol A and B distribution in Soybean (Glycine Max L. Merr) in relation to seed physiology, genetic variability and growing location. J. Agric. Food Chem. 51: 5888-5894.

Sabu, M.C., Smitha, K., \& Kuttan, R., (2002). Anti-diabetic activity of green tea polyphenols and their role in reducing oxidative stress in experimental diabetes. J. Ethnopharmacol. 83: 109-116.

Shimizu, M., Kobayashi, Y., Suzuki, M., Satsu, H., \& Miyamoto, Y., (2000). Regulation of intestinal glucose transport by tea catechins. Biofactors 13: 6165.

Stanely Mainzen Prince, P., Kamalakkannan, N. \& Menon, V.P., (2004). Antidiabetic and antihyperlipidaemic effect of alcoholic Syzigium cumini seeds in alloxan induced diabetic albino rats. J. Ethnopharmacol. 91: 209-213.

Steinberg, D., Parthasarathy, S., \& Carew, T.E., (1989). Beyond cholesterol. Modifications of low-density lipoprotein that increase its atherogenicity. N Eng J Med 320: 915-924.

Tas, S., Sarandol, E., Ziyanok, S., Aslan, K., \& Dirican, M., (2005). Effect of green tea on serum paraoxonase/arylesterase activities in streptozotocin-induced diabetic rats. Nutr. Res. 25:1061-1074.

Tokunagag, S., White, I.R., Frost, C., Tanaka, K., Kono, S, Tokudome, S., et al. (2002). Green tea consumption and serum lipids and lipoprotein in a population of healthy workers in Japan. Ann. Epidemiol. 12:157-65.

Trinder, P., (1969). Enzymatic determination of glucose. Ann. Clin. Biochem. 6- 24.

Tsuchida, T., Itakura, H., \& Nakamura, H., (2002). Reduction of body fat in humans by long-term ingestion of catechins. Progress Med 22: 2189-2203(in Japanese).

Tsuneki, H., Ishizaka, M., Terasawa, M., Wu, J.B., Sasaoko, T., \& kimura, I., (2004). Effect of Green tea on blood glucose levels and serum proteomic patterns in diabetic $(\mathrm{db} / \mathrm{db})$ mice and on glucose metabolism in healthy humans. BMC Pharmacol. 4- 18.

Vinson, J.A., \& Zhang, J., (2005). Black and Green Teas Equally Inhibit Diabetic Cataracts in a Streptozotocin-induced Rat Model of Diabetes. J. Agric. Food Chem. 53:3710-3713.

Waltner-law, M., Wang, X.L., Law, B.K., Hall, R.K., \& Nawano, M., (2002). Epigallocatechin gallate, a constituent of green tea repress hepatic glucose production. J. Biol. Chem. 277:34933-34940.

Wang, D. F., Li, J., Wang, C. H., Zhao, G. W., Jin, Y., Chen, D. D., \&Ye, S. (2000). Study on the component and immune activity of polysaccharides from tea. Journal of Tea Science, 20: 45-50.

Wang, D. F., Wang, C. H., Li, J., \& Zhao, G. W. (2001). Components and activity of polysaccharides from coarse tea. J. Agric. Food Chem., 49:507-510. 
Wu, L.Y., Juan, C.C., Ho, L.T., Hsu, Y.P., \& Hwang, L. S., (2004). Effect of green tea supplementation on insulin sensitivity in Sprague-Dawley rats. J. Agric. Food Chem. 52: 643-648.

Yang, M.H., Wang, C.H., \& Chen, H.L., (2001). Green, Oolong and Black tea extracts modulate lipid metabolism in hyperlipidaemic rats fed high-sucrose diet. J. Nutr. Biochem. 12:14-20.

Yokozawa, T., Nakagawa, T., \& Kitani, K., (2002). Antioxidative Activity of Green Tea Polyphenol in Cholesterol-Fed Rats. J. Agric. Food Chem. 50: 3549-3552.

Young, D.S., (1975).Clin. Chem. 20-5.

Zdunczyk, Z., Frejnagel, S., Wroblewska, M., Juskiewicz, J., Oszmianski, J., \& Estrella, I., (2002). Biological activity of polyphenol extracts from different plant sources. Food Research International 35: 183-186.

Zhang, J., Huang, Y., Hou, T., \& Wang, Y., (2006). Hypoglycemic effect of Artemisia sphaerocephala Krasch seed polysaccharide in alloxan-induced diabetic rats. SWISS. MED. WKLY., 136: 529-532.

Zhang, R., Zhou, J., Jia, Z., (2004). Hypoglycemic Effect of Rehmannia glutinosa oligosaccharide in hyperglycemic and alloxan-induced diabetic rats and its mechanism. J. Ethnopharmacol. 90: 39-43.

\section{ARABIC SUMMERY}

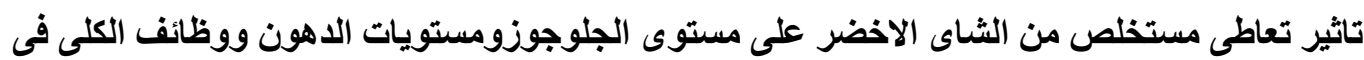

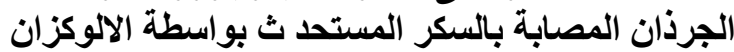

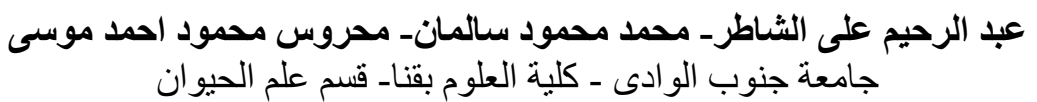

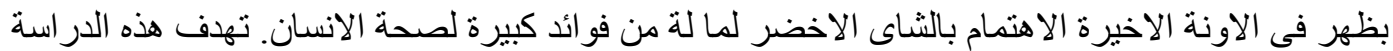

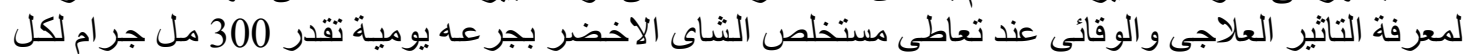

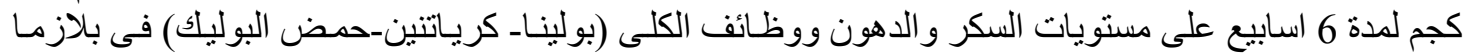

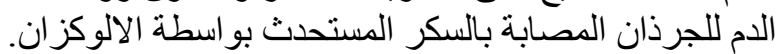

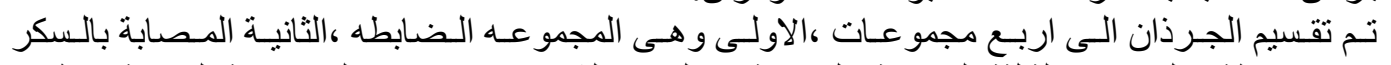

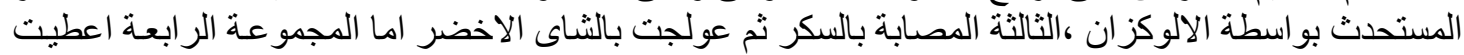

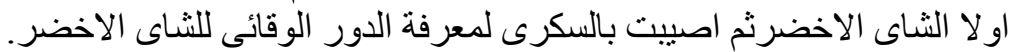

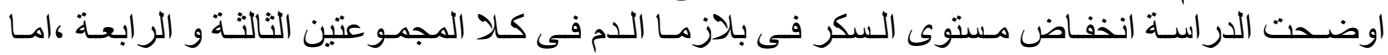

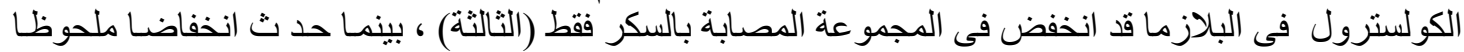

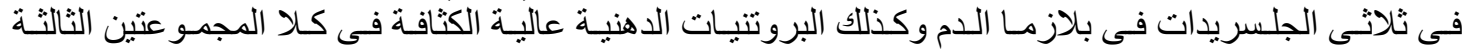

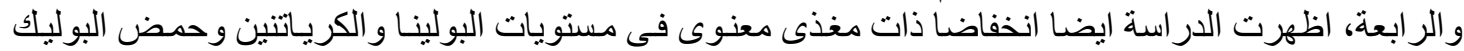

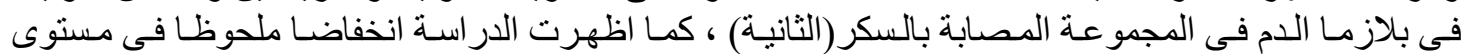

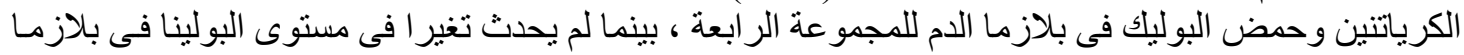

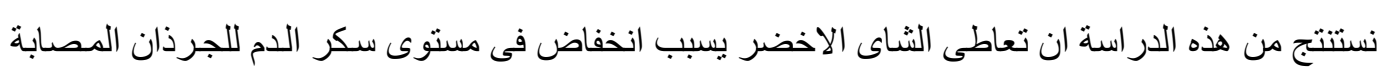

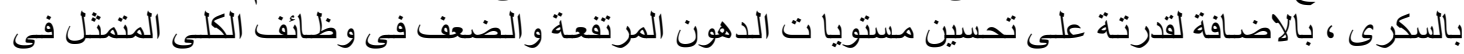
انخفاض مستويات البولينا و الكرياتنتين وحمض لُ الوليك. 